\title{
O Império do Brasil em revista
}

The Brazilian Empire revisited

QUEIROZ, Suely Robles Reis de. Política e cultura no Império brasileiro. São Paulo: Brasiliense, 2010, 159 p.

\section{Marcello Basile}

marcellobasile@ig.com.br

Professor adjunto

Universidade Federal Rural do Rio de Janeiro

Avenida Governador Roberto da Silveira, s/no

26285-060 - Nova Iguaçu - RJ

Brasil

Palavras-chave

Brasil; Política; Cultura.

Keywords

248

Brazil; Policy; Culture. 
Nas últimas duas décadas, a historiografia sobre o Império do Brasil vem sendo notavelmente enriquecida por dezenas de obras que apresentam novas e instigantes perspectivas sobre o período. Não obstante a diversidade de objetos estudados, inclusive a vasta produção sobre a escravidão negra, observa-se em tais trabalhos o privilegiamento de três eixos temáticos: Estado, nação e cidadania. Tais tópicos estão estreitamente inter-relacionados, situados particularmente nas fronteiras das histórias Política, Social e Cultural, abordados à luz de referenciais de análise como, entre outros, cultura política, espaço público, participação popular, vocabulário político e representações simbólicas. ${ }^{1}$ Toda essa pujante produção historiográfica tem trazido indubitáveis avanços para o conhecimento sobre o período, somada a algumas iniciativas relevantes de realização de projetos coletivos de pesquisa, pautados em uma agenda comum de trabalho, ${ }^{2}$ posto que ainda não tenham resultado na elaboração de uma nova interpretação geral acerca do Império brasileiro (PALTI 2009, p. 594).

Convém que se faça, então, um balanço crítico dessas contribuições, sendo primeiramente oportuno, para isso, a realização de uma síntese atualizada sobre o assunto. Bons trabalhos desse tipo já foram produzidos, mas todos escritos e publicados há, pelo menos, mais de dez anos (MONTEIRO 1986; MALERBA 1999; NEVES; MACHADO 1999; BASILE 2000). Uma nova avaliação de conjunto se faz, portanto, necessária, de modo a incorporar os principais avanços registrados na historiografia ao longo das últimas décadas, confrontados com os estudos clássicos sobre o período e, se possível, apontando as lacunas ainda existentes.

O livro em questão de Suely Robles Reis de Queiroz - atualmente professora do Programa de Pós-Graduação em História da Universidade de São Paulo e autora de obras importantes sobre a escravidão no Império e o jacobinismo na Primeira República - é o mais recente trabalho de síntese sobre o Império do Brasil. Constitui o volume 153 da famosa coleção Tudo é História, editada desde o início da década de 1980, pela editora Brasiliense, com o propósito de divulgar, para um público mais amplo do que o estritamente acadêmico, obras que versam sobre temas relevantes da história.

Diante da envergadura da proposta, a autora optou por privilegiar os aspectos políticos e culturais que, em sua visão, marcaram o Brasil imperial, deixando de lado ou em segundo plano, questões de ordem mais propriamente econômica e social. O livro é dividido em cinco capítulos, sendo o último de caráter conclusivo e os demais organizados de acordo com marcos cronológicos tradicionais da história

\footnotetext{
1 Para citar somente algumas obras nessa linha, ver, por exemplo, ALONSO 2002; CARVALHO 2001; DOLHNIKOFF 2005; GOUVÊA 2008; GRAHAM 1997; GRINBERG; SALLES 2009; MELLO 2004; MELLO 2007; MOREL 2005; NEEDELL 2006; NEVES 2003; RIBEIRO 2002; SCHWARCZ 1998; SLEMIAN 2009; SOUZA 1999. 2 Duas grandes iniciativas deste tipo, envolvendo pesquisadores de diversas universidades brasileiras e estrangeiras, devem ser lembradas. A primeira, desenvolvida no âmbito do Centro de Estudos do Oitocentos (atualmente sediado na U.E.R.J.), resultou, até o momento, em três sucessivos projetos financiados pelo PRONEX / CNPq - FAPERJ: Nação e cidadania no Império: novos horizontes (2003-2006), Dimensões da cidadania no século XIX (2006-2009) e Dimensões e fronteiras do Estado brasileiro no século XIX (20092012); os dois primeiros, sob a coordenação de José Murilo de Carvalho (U.F.R.J.) e o terceiro, de Lúcia Bastos Pereira das Neves (U.E.R.J.). A segunda foi realizada sob os auspícios do projeto temático Formação do Estado e da nação: Brasil, C.1780-c.1850, dirigido por István Jancsó (U.S.P.), que contou com apoio da FAPESP, entre os anos de 2005-2009, e foi sediado no Instituto de Estudos Brasileiros da U.S.P. Entre as produções bibliográficas resultantes destas iniciativas estão obras como CARVALHO 2007; CARVALHO; NEVES 2009; CARVALHO; CAMPOS 2011; CARVALHO; PEREIRA; RIBEIRO; VAZ 2011; JANCSÓ 2003; JANCSÓ 2005.
} 
política do período: processo de Independência e Primeiro Reinado (1808-1831); Regência (1831-1840); apogeu do Segundo Reinado (1840-1870); e crise do Império (1870-1889). Certa dose de criatividade ficou por conta da inclusão, em três dos capítulos, de análises sobre o papel desempenhado pela política na vida de três distintas mulheres: a primeira imperatriz do Brasil, Maria Leopoldina; a revolucionária farroupilha Anita Garibaldi; e a musicista Chiquinha Gonzaga.

Dividido em três partes (processo de Independência, Primeiro Reinado e atuação política de dona Leopoldina), o capítulo I começa com uma reflexão acerca dos fatores que levaram ao surgimento do Império brasileiro, visto a partir da recorrente imagem da monarquia como "flor exótica na América". Contudo, embora seja um dos temas mais debatidos na historiografia brasileira, rico em interpretações diversas (RIBEIRO 2000; COSTA 2005; MALERBA 2006), o processo de Independência é retratado sem referência alguma a essas controvérsias, limitando-se a reproduzir a chave explicativa da crise do Antigo Sistema Colonial. Da mesma forma, informações e visões hoje já questionadas por parte da historiografia como exageradas ou simplistas - como a de que cerca de quinze mil pessoas vieram para o Brasil com a corte portuguesa em 1808; a ênfase dada ao protagonismo de São Paulo no processo de emancipação; ou a caracterização do governo de Pedro I como contraditório - são apresentadas sem discussão. Além disso, o texto transcorre com uma descrição bem pontuada, posto que fatual, dos problemas políticos que marcaram o período compreendido nessa seção.

Composto também por três partes, o capítulo II enfoca a fase regencial, 250 abordando, sucessivamente, as mudanças políticas e jurídicas que caracterizaram a época como uma "experiência republicana", as diversas revoltas ocorridas no Brasil e a ação revolucionária de Anita Garibaldi na Farroupilha. Algumas questões, todavia, são tratadas de maneira superficial e sem incorporar as contribuições trazidas pela historiografia recente. Assim, o movimento da Abdicação parece ser uma decorrência natural das práticas autoritárias de Pedro I e dos anseios de nacionalização da Independência; a atuação conflituosa das facções políticas da época, com seus projetos distintos de nação, é praticamente ignorada, assim como a emergência de um espaço público de ação política (uma das marcas mais características do período); as dezenas de revoltas que atravessaram toda a era regencial e todo o país são, por sua vez, reduzidas às quatro mais conhecidas (Cabanagem, Farroupilha, Sabinada e Balaiada). A autora, todavia, escapa da armadilha de encarar a Regência como período meramente anárquico e anômalo na história do Brasil imperial, preferindo, acertadamente, compreendê-lo como momento importante do processo de construção da nação.

Outras três partes compõem o capítulo III, que inicia a análise sobre o Segundo Reinado: a primeira aborda a denominada "década palaciana" (1840 a 1850), na qual o jovem imperador ainda estaria sob influência da chamada facção áulica; a segunda, a época entendida como de "esplendor do Império", o auge da monarquia e momento de maior estabilidade nacional (1850-1870); e a terceira, tratada de modo bem panorâmico, as manifestações culturais produzidas ao longo de todo o período monárquico (música, teatro, cursos superiores, positivismo e romantismo). Aqui também se nota a ausência ou a 
falta de discussão de temas e questões que há muito marcam a historiografia e a própria história do Segundo Reinado, como a imputada semelhança entre liberais e conservadores; a hegemonia saquarema ao longo dos anos de 1837 a 1862; a homogeneidade da elite política imperial; a Guerra do Paraguai; e o mecenato real sobre o Instituto Histórico e Geográfico Brasileiro e sobre a produção artística e literária.

O capítulo IV aborda as duas décadas finais do Império, entendidas como período de declínio da monarquia, quando o consenso sobre o regime e sobre o imperador desfaz-se progressivamente. Assim como os demais, é igualmente dividido em três partes: a primeira, dedicada à desarticulação do escravismo; a segunda, à crise do sistema político imperial; e a terceira, à trajetória singular de Chiquinha Gonzaga. Mais uma vez, observam-se diversas lacunas a respeito de pontos cruciais: o processo de emancipação dos escravos é abordado linear e exclusivamente sob a ótica das chamadas leis abolicionistas; ao movimento republicano, é destinada menos de meia página; a chamada Questão Religiosa ou dos Bispos é apenas mencionada; nada é dito sobre o notável revigoramento, então ocorrido, dos espaços públicos de ação política e, como explicação determinante para a queda do Império, permanece o antigo argumento que salienta a suposta incapacidade de um Estado imperial arcaico de se adequar aos novos ventos da modernidade, ignorando-se, assim, outras linhas de interpretação.

A título de conclusão, o quinto e último capítulo busca assinalar algumas características gerais da política imperial. A autora, todavia, prende-se a ideias há muito questionadas pela historiografia. Postula, assim, a indiferenciação entre liberais e conservadores ao longo do Império, em razão da tendência conciliatória e conservadora de ambos, da mesma forma como reproduz a velha e equivocada tese, já tantas vezes debatida, que apregoa as distorções e os limites do liberalismo no Brasil escravista (como se, em algum outro lugar, houvesse um único e verdadeiro liberalismo).

A despeito dos questionamentos assinalados, o livro de Suely Robles Reis de Queiroz cumpre o papel de apresentar um breve panorama da história política (mais do que da cultural) do Império do Brasil. Parte dos problemas pode ser creditada ao reduzido número de páginas e à louvável proposta de divulgação da obra para além do público especializado. Mas, por outro lado, as lacunas e simplificações são decorrentes, principalmente, da falta de atualização historiográfica. A autora apoia essencialmente sua análise em obras clássicas de inegável valor, como as de Caio Prado Júnior, Octavio Tarquiínio de Souza, Emília Viotti da Costa e os diversos artigos sobre o período monárquico publicados na coleção História geral da civilização brasileira, organizada por Sergio Buarque de Hollanda. Entretanto, quase toda a produção historiográfica da década de 1990 em diante - e mesmo antes - sequer foi mencionada (apenas cinco obras produzidas nesse período constam na bibliografia final). Até mesmo trabalhos seminais, considerados como principais referências sobre a política imperial, foram totalmente ignorados, como os de CARVALHO $(1981 ; 1988)$ e de MATTOS (1987), além de muitos outros (a exemplo dos citados no início da resenha). Com 
isso, grande parte das contribuições e das revisões historiográficas verificadas nas últimas duas ou três décadas não foram incorporadas ao texto. Se a proposta de produzir uma nova síntese sobre o Império brasileiro é desejável e oportuna, esta ficou em parte a dever por não dar a merecida atenção às perspectivas inovadoras diversas, trazidas pela produção historiográfica recente. Afinal, a História muda com o avanço da historiografia.

\section{Referências bibliográficas}

ALONSO, Angela. Ideias em movimento: a geração 1870 na crise do BrasilImpério. São Paulo: Paz e Terra, 2002.

BASILE, Marcello Otávio N. de C. O Império brasileiro: panorama político. In: LINHARES, Maria Yedda (org.). História geral do Brasil. 9a ed. Rio de Janeiro: Campus, 2000.

CARVALHO, José Murilo de. A construção da ordem: a elite política imperial. Brasília: Editora da Universidade de Brasília, 1981.

Teatro de sombras: a política imperial. São Paulo: Vértice; Editora Revista dos Tribunais / Rio de Janeiro: Instituto Universitário de Pesquisas do Rio de Janeiro, 1988.

- Cidadania no Brasil: o longo caminho. Rio de Janeiro: Civilização Brasileira, 2001.

252 (org.). Nação e cidadania no Império: novos horizontes. Rio de Janeiro: Civilização Brasileira, 2007.

; CAMPOS, Adriana Pereira (orgs.). Perspectivas da cidadania no Brasil Império. Rio de Janeiro: Civilização Brasileira, 2011.

; NEVES, Lúcia Maria Bastos Pereira das (orgs.). Repensando o Brasil do Oitocentos: cidadania, política e liberdade. Rio de Janeiro: Civilização Brasileira, 2009.

; PEREIRA, Miriam Halpern; RIBEIRO, Gladys Sabina; VAZ, Maria João (orgs.). Linguagens e fronteiras do poder. Rio de Janeiro: Editora FGV, 2011.

COSTA, Wilma Peres. A Independência na historiografia brasileira. In: JANCSÓ, István (org.). Independência: história e historiografia. São Paulo: Hucitec / Fapesp, 2005.

DOLHNIKOFF, Miriam. O pacto imperial: origens do federalismo no Brasil do século XIX. São Paulo: Globo, 2005.

GOUVÊA, Maria de Fátima Silva. O Império das províncias: Rio de Janeiro, 1822-1889. Rio de Janeiro: Civilização Brasileira, 2008.

GRAHAM, Richard. Clientelismo e política no Brasil do século XIX. Rio de Janeiro: Editora da UFRJ, 1997. 
GRINBERG, Keila; SALLES, Ricardo (orgs.). O Brasil imperial. 3 vs. Rio de Janeiro: Civilização Brasileira, 2009.

JANCSÓ, István (org.). Brasil: formação do Estado e da nação. São Paulo: Hucitec; Fapesp / Ijuí: Unijuí, 2003.

(org.). Independência: história e historiografia. São Paulo: Hucitec / Fapesp, 2005.

MALERBA, Jurandir. O Brasil imperial (1808-1889): panorama da história do Brasil no século XIX. Maringá: Eduem, 1999.

- Esboço crítico da recente historiografia sobre a Independência do Brasil (c.1980-2002). In: MALERBA, Jurandir (org.). A Independência brasileira: novas dimensões. Rio de Janeiro: Editora FGV, 2006.

MATTOS, IImar Rohloff de. O Tempo Saquarema: a formação do Estado imperial. São Paulo: Hucitec / Brasília: Instituto Nacional do Livro, 1987.

MELLO, Evaldo Cabral de. A outra Independência: o federalismo pernambucano de 1817 a 1824. São Paulo: Editora 34, 2004.

MELLO, Maria Tereza Chaves de. A república consentida: cultura democrática e científica do final do Império. Rio de Janeiro: Editora FGV / Edur, 2007.

MONTEIRO, Hamilton M. Brasil Império. São Paulo: Ática, 1986.

MOREL, Marco. As transformações dos espaços públicos: imprensa, atores políticos e sociabilidades na Cidade Imperial (1820-1840). São Paulo: Hucitec, 2005.

NEEDELL, Jeffrey D. The Party of Order: the conservatives, the State, and slavery in the Brazilian Monarchy, 1831-1871. Stanford: Stanford University Press, 2006.

NEVES, Lúcia Maria Bastos Pereira das. Corcundas e constitucionais: a cultura política da Independência (1820-1822). Rio de Janeiro: Revan / Faperj, 2003.

; MACHADO, Humberto Fernandes. O Império do Brasil. Rio de Janeiro: Nova Fronteira, 1999.

PALTI, Elias José. O século XIX brasileiro, a nova história política e os esquemas teleológicos. In: CARVALHO, José Murilo de; NEVES, Lúcia Maria Bastos Pereira das (orgs.). Repensando o Brasil do Oitocentos: cidadania, política e liberdade. Rio de Janeiro: Civilização Brasileira, 2009.

RIBEIRO, Gladys Sabina. Os portugueses na formação da nação brasileira o debate historiográfico desde 1836. In: Ler História, no 38. Lisboa: ISCTE, 2000.

A liberdade em construção: identidade nacional e conflitos antilusitanos no Primeiro Reinado. Rio de Janeiro: Relume Dumará / Faperj, 2002. 
SCHWARCZ, Lilia Moritz. As barbas do imperador: d. Pedro II, um monarca nos trópicos. São Paulo: Companhia das Letras, 1998.

SLEMIAN, Andréa. Sob o império das leis: constituição e unidade nacional na formação do Brasil (1822-1834). São Paulo: Aderaldo \& Rothschild / Fapesp, 2009.

SOUZA, Iara Lis Franco Schiavinatto Carvalho. Pátria coroada: o Brasil como corpo político autônomo - 1780-1831. São Paulo: Unesp, 1999.

254 